\title{
Effect of Non-Pharmacological Interventions on Sleep Quality during Pregnancy among Primigravida
}

\author{
Amera Bekhatro Awad Allah Rashed ${ }^{1 *}$, Amal Khalifa Khalil2, Hanaa Mohamed Abo Shereda ${ }^{3}$ \\ ${ }^{1}$ Assistant Professor, Department of Nursing, College of Applied Medical Sciences, Jouf University-Qurrayat Branch, Sakakah Saudi \\ Arabia \\ 2Lecturer, Maternal and Newborn Health Nursing, Faculty of Nursing / Menoufyia University, Egypt \\ ${ }^{3}$ Lecturer, Psychiatric and Mental Health Nursing, Faculty of Nursing / Menoufyia University, Egypt \\ *Corresponding Author \\ Amera Bekhatro Awad Allah Rashed
}

Article History

Received: 29.08.2019

Accepted: 13.09 .2019

Published: 30.09 .2019

\begin{abstract}
Decreased sleep quality is a common complaint during pregnancy especially among primigravida. Regarding the high incidence of sleep disorders during pregnancy and their adverse effects on maternal and fetal health, it is hazardous to apply pharmaceutical approaches during pregnancy. Relaxation and guided imagery are forms of the non-pharmacological treatments for managing sleep disorders. Aim of the study: was to study the effect of non-pharmacological interventions on sleep quality during pregnancy among primigravida. Methods \& Research Design: a quasi experimental design was used in this study with comparing three groups two study and one control. Subjects: A purposive sample of one hundred and twenty women was recruited. Tools: three tools were used for data collection which named; interviewing questionnaire, Pittsburgh Sleep Quality Index and an evaluation checklist. Results: there was a statistically significant difference between groups regarding daily sleep time, PSQI score and sleep quality after intervention. Conclusion: the first research hypothesis was accepted as it was found that progressive muscle relaxation 'as one of the non-pharmacological interventions' was effective in improving participants sleep quality. Recommendations: Instruct pregnant women about appropriate non-pharmacological interventions which have no side-effects to improve sleep quality.
\end{abstract}

Keywords: Guided Imagery, Muscle Relaxation, Primigravida, Sleep quality.

\section{INTRODUCTION}

\section{Operational Definitions}

Non-Pharmacological Interventions: referring to therapy that does not involve drugs. In this study it referred to progressive muscle relaxation and guided imagery as ways of improving sleep quality [1].

Progressive Muscle Relaxation: it is one of the nursing interventions to release muscle tension it is a method of deep muscle relaxation based on the premise that muscle tension is the body's physiological response to anxiety-provoking thoughts and that muscle relaxation blocks anxiety [2].

Guided Imagery: is the use of relaxation and mental visualization to improve mood and/or physical well-being [3].

Sleep Quality: it can be measured from two perspectives either subjective or objective sleep quality. In this study subjective sleep quality will be tested it is defined as one's perception that they fall asleep easily, get sufficient duration so as to wake up feeling rested, and can make it through their day without experiencing excessive daytime sleepiness. Objective sleep quality is defined by sufficient duration (> 7hrs), high efficiency (> 85\%), and low fragmentation (<25). Using polysomnography "PSG" allows us to add sleep architecture to the equation, whereby "Good" objective sleep quality is defined not only by sufficient duration, high efficiency, and low fragmentation, but also by proper staging of sleep (i.e., cycling through non-REM "rapid eye movement" (stages 1-4) and REM). [4]

Copyright @ 2019: This is an open-access article distributed under the terms of the Creative Commons Attribution license which permits unrestricted use, distribution, and reproduction in any medium for non commercial use (NonCommercial, or CC-BY-NC) provided the original author and source are credited. 
Pregnancy: pregnancy or gestation is the state of carrying a developing embryo or fetus within the female body lasting for 9 months. Late pregnancy is the last 3 months of gestation [5].

Primigravida: it is a term that describes a woman who is pregnant for the first time [5].

According to Maslow's hierarchy of needs, sleep is one of the basic human needs and it may be the most essential one [6]. It is estimated that sleep disorders are more common in women than men during the course of life due to hormonal changes that occur during menstruation, pregnancy, and also menopause [7]. Pregnancy is one of the basic causes of sleep disorders [8]. Decreased sleep quality is one of the common pregnancy complaints as reported by pregnant women in many studies [9]. According to the same reference; such complaint mostly occurring in the third trimester of pregnancy as the mother approaches the end of pregnancy. In the last decades; the incidence of sleep disorders has been reported around 75\% in the third trimester [10]. As reported by many studies; poor sleep quality could directly lead to preterm labor, low birth weight, blood pressure disorders, glucose tolerance disorders, and depression during and after pregnancy [11-15].

The most common used therapeutic methods for sleep disorders are pharmaceutical treatments in which by the suppression of the central nervous system, anxiety and stress levels decrease and the pregnant woman becomes hypnotic and relaxed [16]. Pharmaceutical methods may be extremely contraindicated during pregnancy due to some potential risks for the growing fetus and their impacts on fetal growth and development [17]. So, alternative non- pharmaceutical methods without side effects should substitute pharmaceutical methods for the treatment of such sleep disorders.

Behavioral therapy is one of the non pharmaceutical methods used nowadays for managing sleep problems. Relaxation as one of this therapy can relieve external stressors and has been widely applied in recent years. It is considered a simple, feasible and useful behavioral approach used by nurses all over the world to manage sleep disorders [18-20]. There are various relaxation techniques as progressive muscle relaxation, guided imagery, massage, hypnotism, yoga, music therapy, and breathing techniques [12]. Progressive muscle relaxation is a widely used method; this method has been shown to be effective in decreasing cognitive and physical stress and improving self confidence [19, 21]. As reported by [22] in their study, guided imagery could decrease stress and increase the emotional stability of the participants [22]. Different relaxation techniques may have different impacts on various biological and emotional stressors. However, little researches have been performed to determine which method is most effective in managing pregnancy sleep disorders [18].

Progressive muscle relaxation techniques include full-body relaxation, color exchange, in which a discomfort is given a color and eliminated and listening to restful music or meditative sounds. Such techniques are helpful in many situations in which persons are tense, in pain, highly stressed, or anxious. They can be useful in the treatment of asthma, hyperventilation, high blood pressure, Raynaud's disease, headache, and peptic ulcers [8].

Pregnancy is a stressful event for any women. Stress rate highly increases during the third trimester of pregnancy and near the delivery time. In fact, stress is an indispensable cause of poor sleep quality and other sleep disorders [18]. Morin, C. M et al., [23] introduced methods of improving sleep quality such as progressive muscle relaxation to decrease somatic stress and guided imagery, as well as meditation, for removing distractive thoughts during sleep [23]. Malekzadegan A et al., [24] reported that progressive muscle relaxation plays a role in improving sleep disorders during the third trimester of pregnancy [24]. The basic principle of progressive muscle relaxation is the woman's sitting position. In other terms, the head must be placed along the trunk, the vertebral column must be straight, and the curves should be filled.

Guided imagery is simply the use of one's imagination to promote mental and physical health. It can be self-directed, where the individual puts himself into a relaxed state and creates his own images, or directed by others. When directed by others, an individual listens to a therapist, video, or audiotaped exercise that leads him through a relaxation and imagery exercise. Some therapists also use guided imagery in group settings. Guided imagery is a two-part process. The first component involves reaching a state of deep relaxation through breathing and muscle relaxation techniques. During the relaxation phase, the person closes her eyes and focuses on the slow, in and out sensation of breathing. Or, she might focus on releasing the feelings of tension from her muscles starting with the toes and working up to the top of the head. Relaxation tapes often feature soft music or tranquil, natural sounds such as rolling waves and chirping birds in order to promote feelings of relaxation [11].

Once complete relaxation is achieved, the second component of the exercise is the imagery, or visualization, itself. There are a number of different types of guided imagery techniques, limited only by the imagination. Some commonly used types include relaxation imagery, healing imagery, pain control imagery, and mental rehearsal [11].

During pregnancy, and with the enlargement of the abdomen, the mentioned sitting position without displacement is probably not easy for any woman, and the supine position could easily press the uterine vessels [17-20]. It seems that guided imagery is of major priority since it requires no specific sitting position and could be simply performed in a limited amount of time [18, 19]. Guided imagery is a cognitive behavioral technique in which the individual is guided in imagining a series of experiences for controlling 
stress and balancing negative thoughts [25]. In a study done by [26] mental imagery was a well tolerated method by participants with post traumatic stress disorders, suffering from nightmares and sleep disorders [26]. Moreover, [27] showed a significant correlation between sleep quality of mothers with premature neonates and mental distress; as their results showed that sleep quality improved by performing guided imagery [27]. However; [28] did not report a significant association between pain reductions and progressive muscle relaxation or guided imagery in cancer patients [28]. Urech, C et al., showed that guided imagery resulted in lower heart rate and more relaxation, compared to the other techniques [29].

\section{Significance of the Study}

In the last decades; the incidence of sleep disorders has been reported to be around $75 \%$ in the third trimester [10]. As reported by many studies; poor sleep quality could directly lead to preterm labor, low birth weight, blood pressure disorders, glucose tolerance disorders, and depression during and after pregnancy [11-15]. In addition; pregnancy is a critical period that it is impossible to use pharmaceutical approaches to cope with sleep disorders and improve sleep quality. Such problem may be more difficult to cope with in primigravida. Therefore, it is necessary to find safe methods for improving pregnant women's sleep quality [9]. By reviewing the available body of literature; the researchers found that there are limited studies examined the effect of progressive muscle relaxation and guided imagery as methods of the non-pharmacological interventions for sleep quality among primigravida women. According to the previously mentioned data which stressed the magnitude of the problem of improving sleep quality, the researchers were motivated to undergo this research study.

\section{Aim of the Study}

To study the effect of non-pharmacological interventions on sleep quality during pregnancy among primigravida

The specific study aims were to:

Examine the effect of progressive muscle relaxation on sleep quality during pregnancy among primigravida

Examine the effect of guided imagery on sleep quality during pregnancy among primigravida

\section{Research Hypothesis}

Progressive muscle relaxation 'as one of the non-pharmacological interventions' will improve sleep quality during pregnancy among primigravida as compared to guided imagery.

Guided imagery 'as one of the non-pharmacological interventions' will improve sleep quality during pregnancy among primigravida as compared to progressive muscle relaxation.

\section{METHODS \\ Research Design}

A quasi experimental design was used in this study with comparing two study groups "guided imagery group and progressive muscle relaxation group" with the control group.

\section{Setting}

The study was conducted in two maternal and child health centers at shebin elkoom city, menofyia governorate. These settings were selected as the mentioned city is the governorate capital and known to have the highest population density.

\section{Subjects}

The study sample was assigned to three groups, comprised of 120 pregnant women. Participants were recruited according the following inclusion criteria: 1) primigravidity; 2) gestational age of 29-32 weeks; 3) singleton pregnancy; 4) low-risk pregnancy; 5) no history of infertility; 6) no prior history of mental or physical diseases; 7) literacy; 8) no stressful events within the last six months; 9) no treatments for sleep disorders before pregnancy and 10) no night shifts during the study period.

The exclusion criteria were as follows: 1) unwillingness to continue participation in the study; 2) not performing relaxation exercises once a week; and 3) obstetric problems or stressful events during the study period.

\section{The Sample}

The sample size was determined through the following procedure: Based on post-intervention values of sleep quality reported in [31] for the guided imagery group, $4.56 \pm 1.56$ as an intervention group, $12.56 \pm 2.12$ as a control group and in the progressive muscle relaxation group, $5.90 \pm 1.89$ as an intervention group, the sample size was calculated to be 120 (40 for each group), considering $\mathrm{Cl}=95 \%$ and power= $90 \%$ (10\% dropout).

\section{Maneuver of Intervention Preparatory Phase}


An extensive reviewing of electronic data related to sleep, sleep quality during pregnancy, guided imagery and progressive relaxation was done. A review of literature to collect relevant knowledge pertinent to study participants was also used in developing data collection instruments. Telephone number of each participant was taken for communication and for follow up. Participants were randomly assigned to the study groups (group1: guided imagery, group 2: progressive muscle relaxation and group 3: control group).

\section{Operational Phase}

All participants of the study groups were interviewed three times; the first to explain study purpose, to obtain the oral informed consent and to plan time for other interviews. The second was a training one and done for each group alone. It was for the pre test, and to explain the required intervention through a PowerPoint presentation then educational films were also presented by the researchers. At the end of sessions, a booklet and a CD about the presented content were given to each group's participants for practicing at home. The training session was held for groups of 3-5 participants along two weeks (45-60 minutes per session). The last one was for the post-test and it was four weeks later.

Progressive muscle relaxation was instructed based on Jacobson's method by relaxing and contracting 8 muscle groups (modified for abdominal muscles in pregnancy). Guided imagery was instructed by encouraging positive feelings of peacefulness and safety and guiding individuals to imagine beautiful scenes. The subjects were asked to do the exercises twice a day (once in the morning and once before sleeping at night) for a period of 4 weeks and mark the exercise checklist. The researchers contacted the participants at the end of the first, second, third, and fourth weeks and emphasized the importance of doing regular exercises.

\section{Evaluation Phase}

After four weeks, the researchers evaluate the checklist for completeness. Sleep quality was assessed using PSQI in both groups, and the pre- and post-intervention results were compared. If the participants experienced other sleep disorders (such as apnea, nightmares, narcolepsy, and restlessness leg syndrome, or severe insomnia), they were referred to psychiatrists.

However, if the exercises were not performed correctly and the participants were willing to continue the study, the researchers repeated the training session and then start the four weeks period again.

The intended learning outcomes of the second session were:

Knowledge and understanding

List the importance of guided imagery/progressive muscle relaxation

Recall the steps of guided imagery/progressive muscle relaxation

Intellectual skills

Summarize the role of guided imagery/progressive muscle relaxation in improving sleep quality.

General and transferable skills

Value the importance of guided imagery/progressive muscle relaxation in improving sleep quality during pregnancy.

Attitude

Communicate effectively with the researchers to correctly practice guided imagery/progressive muscle relaxation to improve sleep quality.

Session outline:

Pregnancy

Sleep and sleep hygiene

Non-pharmacological interventions to improve sleep quality

Guided imagery: technique and benefits/ progressive muscle relaxation: technique and benefits

Teaching Materials

PowerPoint presentation

Videos

\section{Data Collection Instruments}

Three tools were used for data collection which named; interviewing questionnaire, Pittsburgh Sleep Quality Index (PSQI) and an evaluation checklist.

The interviewing questionnaire (*): Was used to evaluate sociodemographic data, obstetric and gynecological history and data about current pregnancy.

\section{The Pittsburgh Sleep Quality Index [30]}

This is the gold standard measure of subjective sleep quality. This scale evaluates a person's attitude towards sleep quality in the last four weeks. It includes 9 questions in 7 components of subjective sleep quality, sleep latency, sleep duration, habitual sleep efficiency, sleep disturbance, use of sleep medication, and daytime dysfunction. The items are scored using a Likert scale, ranging from 0 to 3 ( $3=$ the highest negative score). The total score was calculated by summing the scores of components, ranging from 0 to 21 ; scores $\geq 5$ indicate poor sleep quality [30]. This tool was translated by the researchers into Arabic 
Evaluation checklist $\left(^{*}\right)$ : This tool was used to ensure performing the steps of each technique (either guided imagery or progressive relaxation).

$\left.{ }^{*}\right)$ Tool was designed by the researchers and submitted to validity and reliability tests.

Validity

The validity of the instruments was ascertained by a group of subject areas experts, medical and nursing staff who reviewed the instruments for content validity. They were asked also to judge the items for completeness and clarity. Suggestions were incorporated into the instruments.

\section{Reliability}

Test-retest reliability was applied by the researchers for testing the internal consistency of the instruments. It is the administration of the same instruments to the same participants under similar conditions on two or more occasions. Scores from repeated testing were compared.

\section{Piloting the Instruments}

A Piloting was conducted on twelve women to test the applicability of the instruments and to estimate the time needed for data collection. On the basis of the piloting results the researchers determined the feasibility of data collection procedures, developed an interview schedule. The results of the piloting help in refining the interview questionnaire.

\section{Ethical Consideration}

Official steps were taken to obtain a permission to conduct the study, with explanation of the aim and the importance of the study to the centers authorities. An informed verbal consent was obtained from all women before participation in the study. Woman were assured that their information were confidential and only used for study process.

\section{Statistical Data Analysis}

The data collected were tabulated \& analyzed by SPSS (statistical package for the social science) software, statistical

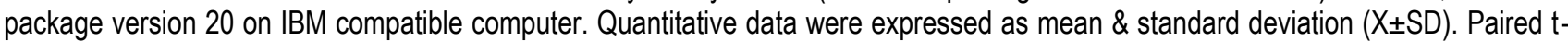
test is a statistical technique used to compare two population means in the case of two samples that are correlated. Qualitative data were expressed as number and percentage (No \& \%) and analyzed by applying chi-square test. Analysis of variance (ANOVA) was used to analyze the differences among group means and their associated procedures. Kruskal-Wallis test was used to assess for significant differences on a continuous dependent variable by a grouping independent variable with the three groups).

P-value at 0.05 was used to determine significance regarding: P-value $>0.05$ to be statistically insignificant (NS), P-value $\leq$ 0.05 to be statistically significant (S) and P-value $\leq 0.001$ to be high statistically significant (HS).

\section{Results}

Table-1: Sociodemographic data of the studied groups

\begin{tabular}{|c|c|c|c|c|c|}
\hline \multirow[t]{2}{*}{ Sociodemographic Data } & \multicolumn{3}{|l|}{ Group } & \multirow[t]{2}{*}{ Chi square test } & \multirow[t]{2}{*}{ P.value } \\
\hline & Control & Guided Imagery & Progressive Relaxation & & \\
\hline \multicolumn{6}{|l|}{ Age } \\
\hline \multirow[t]{2}{*}{$<20$} & 10 & 11 & 10 & \multirow[t]{6}{*}{0.65} & \multirow[t]{6}{*}{$>0.05$} \\
\hline & $25.0 \%$ & $27.5 \%$ & $25.0 \%$ & & \\
\hline \multirow[t]{2}{*}{$21-30$} & 25 & 23 & 26 & & \\
\hline & $62.5 \%$ & $57.5 \%$ & $65.0 \%$ & & \\
\hline \multirow[t]{2}{*}{$31-40$} & 5 & 6 & 4 & & \\
\hline & $12.5 \%$ & $15.0 \%$ & $10.0 \%$ & & \\
\hline \multicolumn{6}{|l|}{ Education } \\
\hline \multirow[t]{2}{*}{ Illiterate } & 10 & 12 & 8 & \multirow[t]{6}{*}{5.9} & \multirow[t]{6}{*}{$>0.05$} \\
\hline & $25.0 \%$ & $30.0 \%$ & $20.0 \%$ & & \\
\hline Secondary & 20 & 19 & 14 & & \\
\hline & $50.0 \%$ & $47.5 \%$ & $35.0 \%$ & & \\
\hline \multirow[t]{2}{*}{ University } & 10 & 9 & 18 & & \\
\hline & $25.0 \%$ & $22.5 \%$ & $45.0 \%$ & & \\
\hline \multicolumn{6}{|l|}{ Occupation } \\
\hline \multirow[t]{2}{*}{ Housewife } & 10 & 15 & 13 & \multirow[t]{4}{*}{1.46} & \multirow[t]{4}{*}{$>0.05$} \\
\hline & $25.0 \%$ & $37.5 \%$ & $32.5 \%$ & & \\
\hline \multirow[t]{2}{*}{ Employee } & 30 & 25 & 27 & & \\
\hline & $75.0 \%$ & $62.5 \%$ & $67.5 \%$ & & \\
\hline \multicolumn{6}{|l|}{ Residence } \\
\hline Rural & 21 & 20 & 10 & 7.6 & $<0.05^{*}$ \\
\hline
\end{tabular}


Amera Bekhatro Awad Allah Rashed et al; South Asian Res J Nurs Health Care; Vol-1, Iss- 1 (Aug-Sep, 2019): 8-17

\begin{tabular}{|l|l|l|l|l|l|}
\hline \multirow{3}{*}{ Urban } & $52.5 \%$ & $50.0 \%$ & $25.0 \%$ & \multirow{3}{*}{} & \\
\cline { 2 - 4 } & 19 & 20 & 30 & & \\
\cline { 2 - 4 } & $47.5 \%$ & $50.0 \%$ & $75.0 \%$ & & \\
\hline
\end{tabular}

$\left.{ }^{*}\right)$ Statistically significant at $p<0.05$

The sociodemographic data are displayed in Table-1. The table shows that participants were not significantly different in terms of age, education and occupation. The majority of participants in all groups were between the ages of 21 to 30 years. As for education; half of participants in the control and guided imagery groups were secondary educated. There was a statistically significant difference between groups regarding residence as more than half of the relaxation group participants were urban residents.

Table-2: Data about present pregnancy

\begin{tabular}{|c|c|c|c|c|c|}
\hline \multirow[t]{2}{*}{ Present Pregnancy } & \multicolumn{3}{|l|}{ Group } & \multirow[t]{2}{*}{ Chi square test } & \multirow[t]{2}{*}{ P.value } \\
\hline & Control & Guided Imagery & Progressive Relaxation & & \\
\hline \multicolumn{6}{|l|}{ Gravidity } \\
\hline \multirow{2}{*}{ Primigravida } & 40 & 40 & 40 & \multirow[t]{4}{*}{-} & \multirow[t]{4}{*}{-} \\
\hline & $100 \%$ & $100 \%$ & $100 \%$ & & \\
\hline \multirow[t]{2}{*}{ Multigravida } & 0 & 0 & 0 & & \\
\hline & $0 \%$ & $0 \%$ & $0 \%$ & & \\
\hline \multicolumn{6}{|l|}{ Gestational age } \\
\hline \multirow[t]{4}{*}{$2^{\text {nd }}$ trimester } & 19 & 17 & 25 & \multirow[t]{4}{*}{3.5} & \multirow[t]{4}{*}{$>0.05$} \\
\hline & $47.5 \%$ & $42.5 \%$ & $62.5 \%$ & & \\
\hline & 21 & 23 & 15 & & \\
\hline & $52.5 \%$ & $57.5 \%$ & $37.5 \%$ & & \\
\hline
\end{tabular}

Table-2 shows data about participants' present pregnancy. The table shows no difference between groups regarding gravidity. This result comes as an inclusion criterion for participation in the study. Regarding the gestational age; and also as an inclusion criterion; all participants were at their 2nd or 3rd trimester of pregnancy.

Table-3: Participants' average daily sleep time per minute before and after the intervention

\begin{tabular}{|l|l|l|l|l|l|}
\hline Average daily sleep time $(\mathrm{min})$ & Group & & & ANOVA test & P value \\
\cline { 2 - 5 } & Control & Guided imagery & Progressive relaxation & & \\
\hline $\begin{array}{l}\text { Before intervention (Mean } \mathbf{4} \text { SD) } \\
\begin{array}{l}\text { After intervention } \\
\text { (Mean } \pm \text { SD) }\end{array}\end{array}$ & $27.62 \pm 23.87$ & $22.49 \pm 21.38$ & $19.03 \pm 20.61$ & 1.34 & $<0.05^{*}$ \\
& $28.63 \pm 22.82$ & $19.20 \pm 10.31$ & $15.13 \pm 10.61$ & & \\
\hline
\end{tabular}

$\left(^{*}\right)$ Statistically significant at $p<0.05$

Table-3 displays Participants' average daily sleep time per minute before and after the intervention. The table shows that there was a statistically significant difference between groups regarding sleep time after the intervention as compared to the preintervention period. The progressive relaxation group participants need to sleep less time during the day due to having enough sleep time at night after the intervention.

Table-4: Comparison of mean PSQI scores in the three groups before and after the interventions and the resulting changes

\begin{tabular}{|l|l|l|l|l|l|}
\hline \multirow{2}{*}{ PSQI } & \multicolumn{2}{|l|}{ Group } & Paired t-test & \multirow{2}{*}{ p.value } \\
\cline { 2 - 5 } & Control & Guided imagery & Progressive relaxation & & \\
\hline PSQI Before intervention & $7 \pm 1.2$ & $8.1 \pm 1.5$ & $7.25 \pm 1.4$ & 0.13 & $>0.05$ \\
\hline PSQI After intervention & $7 \pm 1.2$ & $4.8 \pm 1.14$ & $3.5 \pm 0.78$ & 0.28 & $<0.001^{*}$ \\
\hline The amount of change & $0 \pm 0$ & $3.3 \pm 0.36$ & $3.75 \pm 0.62$ & 0.51 & $<0.001^{*}$ \\
\hline
\end{tabular}

$\left(^{*}\right)$ Statistically significant at $p<0.001$

Table-4 shows a comparison of mean PSQI scores in the three groups before and after the interventions and the resulting changes. Results in this table shows that there was a statistically significant difference between groups after the intervention regarding score of sleep quality index. The progressive relaxation group's participants tend to have a high quality sleep after the intervention indicated by having the lowest PSQI score and the highest amount of score change as compared to other both groups. 
Table-5: Comparison of changes in sleep quality components among the three groups

\begin{tabular}{|c|c|c|c|c|c|}
\hline \multirow{3}{*}{$\begin{array}{l}\text { Components of } \\
\text { Sleep Quality }\end{array}$} & \multicolumn{3}{|l|}{ Groups } & \multirow{3}{*}{$\begin{array}{l}\text { Kruskal-Wallis } \\
\text { test }\end{array}$} & \multirow[t]{3}{*}{ p.value } \\
\hline & Control & Guided imagery & $\begin{array}{l}\text { Progressive } \\
\text { relaxation }\end{array}$ & & \\
\hline & $\begin{array}{l}\text { Amount of changes } \\
\text { Median } \\
\text { (Interquartile range) }\end{array}$ & $\begin{array}{l}\text { Amount of changes } \\
\text { (Interquartile range) }\end{array}$ & $\begin{array}{l}\text { Amount of changes } \\
\text { (Interquartile range) }\end{array}$ & & \\
\hline $\begin{array}{l}\text { Sleep } \\
\text { efficiency }\end{array}$ & $1(2)$ & $-1(1)$ & $-1(2)$ & 2.654 & $P<0.001^{*}$ \\
\hline Sleep duration & $1(1)$ & $-1(1)$ & $-1(2)$ & 8.987 & $\mathrm{P}<0.001^{*}$ \\
\hline $\begin{array}{l}\text { Daytime } \\
\text { dysfunction }\end{array}$ & $1(1)$ & $-1(1)$ & $-1(2)$ & 7.945 & $P<0.001^{*}$ \\
\hline Sleep latency & $0(1)$ & $-1(1)$ & $0(1)$ & 8.541 & $\mathrm{P}<0.001^{*}$ \\
\hline $\begin{array}{l}\text { Sleep } \\
\text { disturbances }\end{array}$ & $0(0.75)$ & $0(1)$ & $1(2)$ & 9.170 & $P<0.001^{*}$ \\
\hline $\begin{array}{l}\text { Subjective } \\
\text { sleep quality }\end{array}$ & 1(1) & $-1(1)$ & $1(2)$ & 7.709 & $P<0.001^{*}$ \\
\hline
\end{tabular}

$\left(^{*}\right)$ Statistically significant at $p<0.001$

Table-5 represents a comparison of changes in sleep quality components among the three groups. It is clearly noticed that there was a significant difference in the components of sleep quality between the control and intervention groups $(P<0.001)$.

The two intervention groups showed a significant difference in terms of sleep efficiency, sleep duration, daytime dysfunction, sleep disturbances and subjective sleep quality. Progressive muscle relaxation had a more significant impact on these components, compared to guided imagery. As use of sleeping medications underwent no change after the study as all participants were not taking such drugs due to being pregnant, it is not mentioned in Table- 5 .

In sum and based on results displayed in tables 3, 4 and 5; the first hypothesis is accepted while the second one is rejected. This means that progressive muscle relaxation as one of the non-pharmacological interventions was effective in improving participants sleep quality among primigravida women.

\section{DISCUSSION}

Sleep disorders are more common in women than men due to hormonal changes during menstrual cycle, pregnancy, and menopause [6]. Pregnancy is one of the causes of sleep disorders [8]. Decreased sleep quality is one of the common complaints during pregnancy [9], mostly occurring in the third trimester of pregnancy as the mother approaches the end of pregnancy. In fact, the incidence of sleep disorders has been reported around $75 \%$ in the third trimester [10]. Poor sleep quality could be related to preterm labor, low birth weight, blood pressure disorders, glucose tolerance disorders, and depression during and after pregnancy [15]. The most common therapeutic methods for sleep disorders are pharmaceutical treatments in which by the suppression of the central nervous system, anxiety and stress levels decrease and the patient becomes hypnotic and relaxed [11].

However, pharmaceutical methods are contraindicated during pregnancy due to some potential risks for the fetus and their impacts on fetal growth and development [19]. Therefore, alternative non - pharmaceutical methods with no side - effects should substitute pharmaceutical methods for the treatment of sleep disorders. Behavioral therapy is one of non- pharmaceutical methods for sleep problems. Relaxation, which relieves external stressors, has been widely applied in recent years and is considered a simple, feasible and useful behavioral approach [29]. There are various relaxation techniques such as progressive muscle relaxation, guided imagery, massage, hypnotism, yoga, music therapy, and breathing techniques [13]. Progressive muscle relaxation is a widely-applied method, which has been shown to be effective in decreasing physical and cognitive stress and improving self-confidence [19].

The current study was conducted with aim of studying the effect of non-pharmacological interventions on sleep quality during pregnancy among primigravida. Based on the current findings; the first study hypothesis was accepted. The researchers found that both progressive muscle relaxation and guided imagery improved sleep quality of pregnant women; however, sleep quality was high among the guided imagery group participants as compared to progressive muscle relaxation. The scores of sleep components also improved in both intervention groups. 
As for the participants' age; the majority of them at the three groups were at the age group of 21-30 years and this comes in accordance with [10] who studied disturbed sleep and inflammatory cytokines in depressed and non-depressed pregnant women in Canada and reported studying similar age group. The current study findings revealed that about half of the studied participants were secondary educated. This finding is similar to that of [29] who studied the effects of relaxation on psychobiological wellbeing during pregnancy among Australian women.

Nearly half of the studied samples were employee, which is like a finding reported by [26] who conducted their study at USA about relaxation rehearsal therapy for chronic nightmares in sexual assault survivors with posttraumatic stress disorder. Regarding the residence, the current results revealed a statistical difference between progressive relaxation group compared to other groups. Three fourths of this group participants were urban residents. This is similar to findings of [18] who conducted a study at Ahsaa about the effect of relaxation and mental imagery and relaxation therapy on anxiety and hopefulness in women with breast cancer and published urban resident participants.

In relation to the present pregnancy data of the studied participants; and as a main inclusion criterion; all participants were primipara. Malekzadegan A et al., [24] studied the effect of relaxation on insomnia during third trimester among Iranian pregnant women. All participants were either at their second or third trimester of pregnancy which was also an inclusion criterion. The more pregnancy advance, the more complain from sleep disturbance and this is why the researchers selected these pregnancy stages. Urech, $C$ et al., [29] who studied the effects of relaxation on psychobiological wellbeing during pregnancy among Australian women also reported selecting this gestational age for the same cause.

Pertaining to participants' average daily sleep time per minute before and after the intervention; the current findings showed that there was a statistically significant difference between groups regarding sleep time after the intervention as compared to the preintervention period. The progressive relaxation group participants need to sleep less time during the day due to having enough sleep time at night after the intervention. On one hand; such findings were agreed upon by [26] who conducted their study at USA about relaxation rehearsal therapy for chronic nightmares in sexual assault survivors with posttraumatic stress disorder and reported that, the effectiveness of relaxation technique in improving the sleep quality of patients with post -traumatic stress disorders.

On the other hand; these findings are contradicted to that of [27] who studied guided imagery: an innovative approach to improve sleep quality among Netherland pregnant women as they reported that guided imagery group participants need short naps as they could sleep well at night. The contradiction is seen to be related to the difference in the sample nature as [27] studied women at their first trimester who already tended to have high sleep quality than those in the second or third as the current study ones.

Regarding the changes in participants sleep quality expressed in terms of PSQI scores; results showed that the progressive muscle relaxation group's participants tend to have a high quality sleep after the intervention indicated by having the lowest PSQI score and the highest amount of score change as compared to other groups. On one hand; this is supported by [31] who compared the effects of progressive muscle relaxation and guided imagery on sleep quality in primigravida women referring to Mashhad health care centers, Iran as the study results revealed a significant difference between the two intervention groups regarding the score of PSQI before and after the intervention. Skouteris, $\mathrm{H}$ et al., [32] reported similar findings through assessing sleep during pregnancy in a study across two time points examining the Pittsburgh sleep quality index and associations with depressive symptoms among Europeans. Skouteris, $\mathrm{H}$ et al., [32] reported that participants were trained for progressive muscle relaxation using one session and were followed-up and the results indicated the effectiveness the method even after one session.

On the other hand; [33] studied behavioral-educational intervention to promote maternal and infant sleep among African women and contradicted the current findings as they recently published that "it could not be definitely identified which method is preferred for improving sleep quality". The contradiction comes from that the same woman was asked to do both interventions so the result couldn't be rationalized by definite intervention.

\section{CONCLUSION}

In the light of the current study findings, it can be concluded that the first research hypothesis is accepted while the second one is rejected. The current findings revealed that progressive muscle relaxation 'as one of the non-pharmacological interventions' was effective in improving participants sleep quality among primigravida women.

\section{RECOMMENDATIONS}

Establish an ante-natal plan for assessing and detecting sleep problems beside routine care.

Plan with the maternal and child health center authority for a teaching class to increase primigravida women's knowledge about pregnancy and its effects on vital functions including sleep.

Instruct pregnant women about appropriate non-pharmacological interventions which have no side-effects to improve sleep quality. 
Provide training sessions to primigravida women about how to perform appropriate techniques of non-pharmacological interventions to improve their sleep quality.

\section{ReferenCes}

1. Field, T., Hemandez-Reif, M., Hart, S., Theakston, H., Schanberg, S., \& Kuhn, C. (1999). Pregnant women benefit from massage therapy. Journal of Psychosomatic Obstetrics \& Gynecology, 20(1), 31-38.

2. Stuber, K. J., \& Smith, D. L. (2008). Chiropractic treatment of pregnancy-related low back pain: a systematic review of the evidence. Journal of manipulative and physiological therapeutics, 31(6), 447-454.

3. Goodwin, A., Astbury, J., \& McMeeken, J. (2000). Body image and psychological well-being in pregnancy. A comparison of exercisers and non-exercisers. Australian and New Zealand journal of obstetrics and gynaecology, 40(4), 442-447.

4. Littner, M., Kushida, C. A., Anderson, W. M., Bailey, D., Berry, R. B., Davila, D. G., ... \& Wise, M. (2003). Practice parameters for the role of actigraphy in the study of sleep and circadian rhythms: an update for 2002. Sleep, 26(3), 337-341.

5. Quijano, C. E., \& Abalos, E. (2005). Conservative management of symptomatic and/or complicated haemorrhoids in pregnancy and the puerperium. Cochrane Database of Systematic Reviews, (3).

6. Sadock, B. J., Kaplan, H., \& Sadock, V. (2007). Kaplan \& Sadock's synopsis of psychiatry behavioral sciences, Rezaee, F.10th ed. Tehran: Arjmand; 149-154.

7. Moline, M., Broch, L., \& Zak, R. (2004). Sleep problems across the life cycle in women. Current treatment options in neurology, 6(4), 319-330.

8. Schutte-Rodin, S., Broch, L., Buysse, D., Dorsey, C., \& Sateia, M. (2008). Clinical guideline for the evaluation and management of chronic insomnia in adults. Journal of clinical sleep medicine, 4(05), 487-504.

9. Tsai, S. Y., Lin, J. W., Kuo, L. T., \& Thomas, K. A. (2012). Daily sleep and fatigue characteristics in nulliparous women during the third trimester of pregnancy. Sleep, 35(2), 257-262.

10. Okun, M. L., Luther, J. F., Wisniewski, S. R., \& Wisner, K. L. (2013). Disturbed sleep and inflammatory cytokines in depressed and nondepressed pregnant women: an exploratory analysis of pregnancy outcomes. Psychosomatic medicine, 75(7), 670-681.

11. Chang, J. J., Pien, G. W., Duntley, S. P., \& Macones, G. A. (2010). Sleep deprivation during pregnancy and maternal and fetal outcomes: is there a relationship?. Sleep medicine reviews, 14(2), 107-114.

12. Williams, M. A., Miller, R. S., Qiu, C., Cripe, S. M., Gelaye, B., \& Enquobahrie, D. (2010). Associations of early pregnancy sleep duration with trimester-specific blood pressures and hypertensive disorders in pregnancy. Sleep, 33(10), 1363-1371.

13. Jahanpak, N., Razmjoo, N., Rezaei Ardani, A., Mazloum, S. R., \& Bonakdaran, S. (2013). The relationship between sleep duration and glucose challenge test results in pregnant women without risk factors of diabetes. The Iranian Journal of Obstetrics, Gynecology and Infertility, 16(60), 9-17.

14. Rad, P., Amir Ali Akbari, S., Sadeghniiat, K., \& Alavi Majd, H. (2011). Relationship between sleep disorder and pregnancy depression in primigravidae referring to health-treatment centers of Ahvaz Jundishapur University of Medical Sciences in 2010. SSU_Journals, 19(4), 454-462.

15. Alipour, Z., Lamyian, M., \& Hajizadeh, E. (2012). Sleep quality in late pregnancy and postpartum depression. The Iranian Journal of Obstetrics, Gynecology and Infertility, 14(8), 39-47.

16. Timby, B. K. (2009). Fundamental of nursing skills and concepts (9th ed. Philadelphia: Lippincott Williams \& Wilkins; 463-471.

17. Cunningham, F. G., Leveno, K. J., Bloom, S. L., Hauth, J. C., Rouse, D. J., \& Spong, C. Y. (2010). Hematological disorders. Williams obstetrics, 23rd ed. Tehran: Golban; 409-414.

18. Hamid, N. (2012). The effect of relaxation and mental imagery and relaxation therapy on anxiety and hopefulness in women with breast cancer in Ahvaz. Asian Journal of Medical and Pharmaceutical Researches, 2(1), 10-15.

19. Alwan, M., Zakaria, A., Rahim, M. A., Hamid, N. A., \& Fuad, M. (2013). Comparison between two relaxation methods on competitive state anxiety among college soccer teams during pre-competition stage. International Journal of Advanced Sport Sciences Research, 1(1), 90-104.

20. Davis, M. (2005). Tutorial relaxation and stress reduction. Tehran: Tabib, 78-81.

21. Everly, G. S., \& Lating, J. M. (2012). A clinical guide to the treatment of the human stress response, 3rd ed. New York: Springer; 186-189.

22. Watanabe, E., Fukuda, S., Hara, H., \& Maeda, Y. (2006). Differences in relaxation by means of guided imagery in a healthy community sample. Alternative therapies in health and medicine, 12(2), 60-68.

23. Morin, C. M., Bootzin, R. R., Buysse, D. J., Edinger, J. D., Espie, C. A., \& Lichstein, K. L. (2006). Psychological and behavioral treatment of insomnia: update of the recent evidence (1998-2004). Sleep, 29(11), 1398-1414.

24. Malekzadegan, A., Morad, K. M., Ashayeri, H., \& Haghani, H. (2010). Effect of relaxation on insomnia during third trimester among pregnant women. Journal of Nursing, 23(64):52-58.

25. Apóstolo, J. L. A., \& Kolcaba, K. (2009). The effects of guided imagery on comfort, depression, anxiety, and stress of psychiatric inpatients with depressive disorders. Archives of psychiatric nursing, 23(6), 403-411.

26. Krakow, B., Hollifield, M., Johnston, L., Koss, M., Schrader, R., Warner, T. D., ... \& Cheng, D. (2001). Imagery rehearsal therapy for chronic nightmares in sexual assault survivors with posttraumatic stress disorder: a randomized controlled trial. Jama, 286(5), 537-545.

27. Schaffer, L., Jallo, N., Howland, L., James, K., Glaser, D., \& Arnell, K. (2013). Guided imagery: an innovative approach to improving maternal sleep quality. The Journal of perinatal \& neonatal nursing, 27(2), 151-159. 
28. Kwekkeboom, K. L., Wanta, B., \& Bumpus, M. (2008). Individual difference variables and the effects of progressive muscle relaxation and analgesic imagery interventions on cancer pain. Journal of pain and symptom management, 36(6), 604-615.

29. Urech, C., Fink, N. S., Hoesli, I., Wilhelm, F. H., Bitzer, J., \& Alder, J. (2010). Effects of relaxation on psychobiological wellbeing during pregnancy: a randomized controlled trial. Psychoneuroendocrinology, 35(9), 1348-1355.

30. Buysse, D. J., Reynolds III, C. F., Monk, T. H., Berman, S. R., \& Kupfer, D. J. (1989). The Pittsburgh Sleep Quality Index: a new instrument for psychiatric practice and research. Psychiatry research, 28(2), 193-213.

31. Golmakani, N., Seyed Ahmadi Nejad, F. S., Shakeri, M. T., \& Asghari Pour, N. (2015). Comparing the Effects of Progressive Muscle Relaxation and Guided Imagery on sleep quality in primigravida women referring to Mashhad health care centers1393. Journal of Midwifery and Reproductive Health, 3(2), 335-342.

32. Skouteris, H., Wertheim, E. H., Germano, C., Paxton, S. J., \& Milgrom, J. (2009). Assessing sleep during pregnancy: a study across two time points examining the Pittsburgh Sleep Quality Index and associations with depressive symptoms. Women's health issues, 19(1), 45-51.

33. Stremler, R., Hodnett, E., Lee, K., MacMillan, S., Mill, C., Ongcangco, L., \& Willan, A. (2006). A behavioral-educational intervention to promote maternal and infant sleep: a pilot randomized, controlled trial. Sleep, 29(12), 1609-1615. 